\title{
Theoretical EPR study of Nitroindazoles: 3-Alkoxy, 3-Hydroxy and 3-Oxo Derivatives
}

\author{
Jorge Rodríguez-Becerra, ${ }^{a, b}$ Claudio Olea-Azar, ${ }^{*, b}$ Gerald Zapata-Torres, ${ }^{b}$ \\ Fernando Mendizabal, ${ }^{c}$ Mercedez Gonzáles ${ }^{d}$ and Hugo Cerecetto ${ }^{d}$ \\ ${ }^{a}$ Departamento de Química, Facultad de Ciencias Básicas, Universidad Metropolitana de Ciencias \\ de la Educación, Chile \\ ${ }^{b}$ Departamento de Química Inorgánica y Analítica, Facultad de Ciencias Químicas y \\ Farmacéuticas, Universidad de Chile, Chile \\ 'Departamento de Química, Facultad de Ciencias, Universidad de Chile, Chile \\ ${ }^{d}$ Departamento de Química Orgánica, Facultad de Ciencias/Facultad de Química, \\ Universidad de la Republica, Uruguay
}

\begin{abstract}
Um estudo de DFT em derivados 5-NI foi realizado em diferentes níveis de teoria, a fim procurar a melhor metodologia para calcular constantes de acoplamento hiperfinas (hfccs), distribuições da densidade da rotação e propriedades eletrônicas, sabendo-se que é difícil obter boa concordância entre os valores de hfccs calculados e experimentais para compostos radicais centrados no nitrogênio. Os híbridos funcionais diferentes B1LYP, B3LYP e PBE0 foram usados conjuntamente com vários meios para aumentar o tamanho da base estudada. O modelo de C-PCM foi considerado para interações do soluto-solvente. As comparações de nossos cálculos com os dados experimentais precedentes obtidos por meio de medidas de EPR e raios-X confirmaram que esta aproximação computacional representa importante avanço. Nossos resultados indicaram que os efeitos solventes e a consideração de funções difusas são os fatores mais importantes no cálculo de constantes hiperfinas de acoplamento para este sistema nitro-heterocíclico. Foi verificado também que algumas propriedades eletrônicas calculadas como orbital de LUMO, funções condensadas de Fukui para ataques nucleofílico e afinidade de elétron não são correlacionadas como esperado com a atividade biológica.
\end{abstract}

A DFT study on 5-NI derivatives was carried out at different levels of theory, in order to seek for the best methodology that helps us to calculate hyperfine coupling constants (hfccs), spin density distributions and electronic properties, since it is difficult to obtain a good agreement between calculated and experimental hfccs for nitrogen center radical compounds. Different functional hybrids namely B1LYP, B3LYP and PBE0 were used in conjunction with various medium to large size basis sets. C-PCM model was considered for solute-solvent interactions. Comparisons of our calculations with previous experimental data obtained from EPR and X-ray techniques confirmed that this computational approach represents an important aid. Our results indicated that solvent effects and consideration of diffuse functions are the most important factors on the calculation of hyperfine coupling constants for this nitro-heterocyclic system. Also, we found that some electronic properties calculated (LUMO orbital, condensed Fukui functions for nucleophilic attacks and electron affinity) do not correlate as expected with the biological activity.

Keywords: DFT, hyperfine coupling constants (hfccs), 5-nitroindazole, Trypanosoma cruzi

\section{Introduction}

It is known that the electron paramagnetic resonance spectroscopy is widely accepted as a powerful experimental

*e-mail: colea@uchile.cl technique to directly detect and characterize free radicals whose persistency allows the acquisition of their EPR spectra. Besides, it provides a direct measure of the distribution of the unpaired spin density. ${ }^{1}$ Unfortunately, the appropriate interpretation of some signals is not straightforward due to the presence of a large number of 
lines. In such cases additional theoretical methods are welcome to streamline the hyperfine coupling constants (hfccs) assignment, obtained from the full spectral analysis. For instance, in the case of 5-nitroindazole (5-NI), ${ }^{2}$ JNI 4 (see Figure 1 and 2), we found that the nitro anion radical spectrum displays eighteen signals, distributed into six triplets. This spectrum can be interpreted in terms of one doublet accounting for one hydrogen atom $(\mathrm{H}-4)$ and two triplets that could be assigned to two nitrogen atoms: one

\begin{tabular}{|c|c|c|c|c|}
\hline & A & & \multicolumn{2}{|l|}{ B } \\
\hline $5-\mathrm{NI}$ & Structure & $\mathrm{R}^{1}$ & $\mathrm{R}^{2}$ & Y \\
\hline JNI 1 & A & $\mathrm{H}$ & $\mathrm{N}\left(\mathrm{CH}_{2}\right)_{4} \mathrm{~S}$ & $\mathrm{O}$ \\
\hline JNI 2 & B & ------- & ------- & $\mathrm{O}$ \\
\hline JNI 3 & B & ------ & ------ & $\mathrm{CH}_{2}$ \\
\hline JNI 4 & $\mathbf{A}$ & $\mathrm{Me}$ & $\mathrm{NH}\left(\mathrm{CH}_{2}\right)_{3} \mathrm{CH}_{3}$ & $\mathrm{CH}_{2}$ \\
\hline JNI 6 & A & $\mathrm{Bn}$ & $\mathrm{N}\left(\mathrm{CH}_{2}\right)_{4} \mathrm{~S}$ & $\mathrm{O}$ \\
\hline JNI 20 & A & $\mathrm{Bn}$ & $\mathrm{N}\left(\mathrm{CH}_{2}\right)_{5}$ & $\mathrm{CH}_{2}$ \\
\hline JNI 21 & $\mathbf{A}$ & $\mathrm{Bn}$ & $\mathrm{N}\left(\mathrm{CH}_{3}\right)_{2}$ & $\mathrm{O}$ \\
\hline
\end{tabular}

Figure 1. Chemical structure of family 5-nitroindazole derivatives.

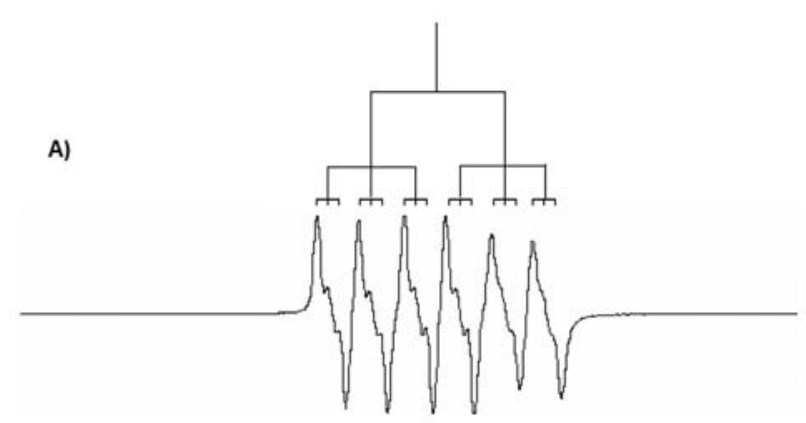

B)

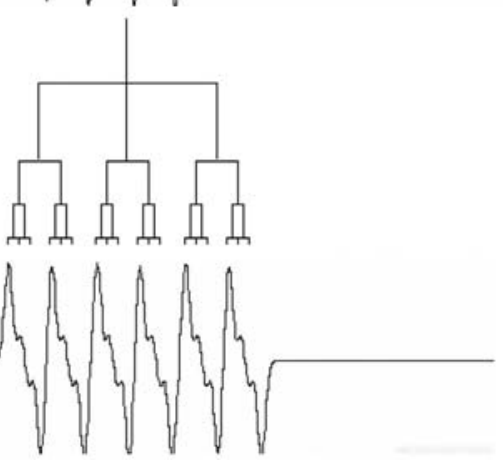

Figure 2. EPR simulated hyperfine patterns: A) nitro anion radical spectrum simulated in terms of one doublet accounting for one hydrogen atom (H-4) and two triplets assigned to two nitrogen atoms; B) nitro anion radical spectrum simulated in terms of one triplet assigned to the nitro group, one doublet assigned to one hydrogen atom and one triplet accounting for two hydrogen atoms. belonging to the nitro group and other to the indazole ring. However, the same pattern can be interpreted in terms of one triplet assigned to the nitro group, one doublet assigned to hydrogen atom $(\mathrm{H}-4)$ and one triplet accounting for two hydrogen atoms (H-6 and $\mathrm{H}-7)$. Experimentally, EPR spectra for many studied nitroheterocycles like ours, have been interpreted on the basis of hfccs typical for nitroaromatic radicals, in which the nitrogen atom of nitro group is characterized by a triplet with the larger hfcc (about $12 \mathrm{G})^{3}$

In this sense, calculations of hfccs might offer a valuable support to the experimental work, providing a computational framework that in turn could give reliable structures and magnetic properties provided a correct hfccs assignation. Density functional theory methods (DFT) are recognized for achieving reasonable predictions of EPR properties with excellent levels of confidence: for this purpose different model chemistries have recently been studied and developed. ${ }^{4,5}$ On this base, we decided to perform a systematic study of the EPR features for several nitroindazole radicals with biological and potential trypanocidal activity. Three density functional hybrids were tested such as B3LYP functional which has been validated in a number of studies of organic radicals. ${ }^{6-8}$ B1LYP functional entirely calculated from DFT, which considers the contribution to the electronic correlation..$^{9,10}$ and PBE1PBE functional, which uses in their description a $25 \%$ of exchange and $75 \%$ of electronic correlation. ${ }^{11}$ It is now well established that computational models based on density functional theory (DFT) are particularly suitable for the analysis of the structure and magnetic properties of open-shell species. ${ }^{12}$

On the other hand, due to the importance of the electronic parameters of the 5-nitroheterocycles on the antichagasic activity and the mechanisms of reaction involving free radicals, ${ }^{13-16}$ we investigated the two electronic states (neutral and radical) of selected nitroindazoles to shed light into the mechanism of protection. In order to perform a preliminary quantitative structure-activity relationship study with these nitroindazole derivatives, we determined different electronic and thermodynamic properties.

\section{Methods}

\section{Computational details}

A conformational search for each of 5-NI derivatives was performed, using molecular mechanics methods (MMFF) as implemented in Spartan' 04, to find the minimum energy structures with the highest abundance conformer population in the gas phase. ${ }^{17,18}$ Furthermore, geometry 
optimization for each selected conformer was performed by means of density functional theory (DFT) as implemented in the GAUSSIAN' 03 package. ${ }^{19}$ All the optimizations for the neutral and radical species were performed using Becke's three parameter exact exchange functional (B3) ${ }^{20}$ combined with gradient corrected correlation functional of Lee-Yang-Parr (LYP) ${ }^{21}$ of DFT method (U)B3LYP/6$31 \mathrm{~g}(\mathrm{~d}, \mathrm{p})$, in vacuum and with conductorlike polarizable continuum model (C-PCM) solvent methodology, ${ }^{22}$ using DMSO as a solvent.

Computations were performed using different basis sets of contracted Gaussian functions, namely $6-31 \mathrm{G}^{* *}$, 6-31+G, 6-311G**, EPR-III, IGLO-II and IGLO-III. Additionally, we add six components for d functions in each basis set, because recent reports indicate that these additions improve the prediction of nitrogen hfccs. ${ }^{8,23}$ All calculations carried out under the unrestricted formalism, gave $\left\langle S^{2}\right\rangle$ values lower than 0.7615 , implicating a spin contamination less than of $2.0 \%$.

The calculations for the electronic descriptors were performed employing the better model chemistry obtained in the computing of hfccs. In this sense, we calculate the energy of the lowest unoccupied molecular orbital (LUMO), the condensed Fukui nucleophilic attack functions and the electron affinity (EA). Besides, we included properties related with hydrophobicity of the compounds such as dipole moments and the partition coefficient in octanol/ water.

\section{Results and Discussion}

\section{Structural and hyperfine coupling constants calculations}

It is known that hfccs calculation is affected by several geometrical factors such as bond lengths, bond and dihedral angles. ${ }^{24}$ Hermosilla et al. ${ }^{8}$ in a recent report have studied the hfccs for a data set of 109 nitrogen radicals and they concluded that the combination of the B3LYP functional with the $6-31 \mathrm{G}^{*}$ basis set including $6 \mathrm{D}$ functions was very accurate for predicting nitrogen hfccs of moderate and large size radicals. ${ }^{7}$ It is important to point out that within this data set only anions of nitroalkanes were considered to represent the nitro compounds, which shown very good agreement between experimental and theoretical hfccs when the 6-31G* basis set is used. Additionally, it is important to consider that the frequently experimental values of hfccs for nitroheterocyclic compounds are reported using polar solvents. The best conformer obtained was evaluated using different basis sets including solvent effects. B3LYP/6-31(d,p) was the methodology that showed the best agreement with the $\mathrm{X}$-ray experimental data available (for JNI 1).

Table 1 summarizes the calculated and experimental geometrical data. Noticeable differences were found on the dihedral angle of the poly(oxo)methylenic dialkylamine chain (see Figure 1). Consequently, the radical species were optimized applying a similar optimization methodology (UB3LYP/6-31G(d,p) and using the same conformers as the case of neutral species. The geometrical data calculated for both neutral and anion radical species, showed a slight increase in the $\mathrm{N}-\mathrm{O}$ bond length and in the $\mathrm{N}-5$ ' -6 ' angle, altogether with a slight decrease in the $\mathrm{N}-5$ ' bond length as in the $\mathrm{O}-\mathrm{N}-\mathrm{O}$ angle (see Table 1). Despite of this fact, the methodology used yield values of hfccs far from the experimental ones (see Table 2). This might be due to an excessive underestimation on the spin density of the nitrogen on the nitro group and/ or an overestimation on the spin density of the aromatic hydrogen $\mathrm{H}-4$ leading to an erroneous interpretation of the EPR as shown in Figure 2A. However, the EPR spectra of nitroaromatic radicals are characterized by a triplet of larger hfcc assigned to nitrogen atom of the nitro group. ${ }^{3}$ In addition, our results indicated that for the nitrogen of the nitro group of nitroindazole radicals, large discrepancies between experimental and theoretical values using larger basis set in vacuum (IGLO III, EPRII, 6-311**) are also obtained. Similar discrepancies were previously analyzed for alkylnitroxyl radicals. ${ }^{8,23}$

Table 1. Selection of calculated and experimental geometrical data: bond length $(\stackrel{\AA}{\mathbf{A}})$, angle $\left(^{\circ}\right)$ and y dihedral $\left({ }^{\circ}\right)$ by JNI 1 derivative

\begin{tabular}{|c|c|c|c|c|c|c|c|c|c|c|c|c|c|c|}
\hline JNI 1 & $1^{\prime}-2^{\prime c}$ & $2^{\prime}-3^{\prime c}$ & $5^{\prime}-\mathrm{N}^{\mathrm{c}}$ & $\mathrm{O}-\mathrm{N}^{\mathrm{c}}$ & $3-4^{c}$ & $7^{\prime} \mathrm{a}-1^{\prime}-2^{\prime} d$ & $1^{\prime}-2^{\prime}-3^{\prime} d$ & $\mathrm{O}-\mathrm{N}-\mathrm{O}^{\mathrm{d}}$ & N- $5^{\prime}-6^{\prime d}$ & $3^{\prime}-2^{\prime}-1^{\prime}-5^{c}$ & $1^{\prime}-2^{\prime}-3^{\prime}-O^{d}$ & $\mathrm{~N}-1-2-3^{\mathrm{d}}$ & $\mathrm{O}-\mathrm{N}-5^{\prime}-6^{\prime} \mathrm{d}$ & $2-3-4-5^{d}$ \\
\hline B3LYP/6-31G & 1.407 & 1.327 & 1.457 & 1.267 & 1.451 & 111.2 & 105.5 & 123.5 & 118.5 & 179.0 & 179.6 & 84.1 & 0.6 & 172.5 \\
\hline B3LYP/6-31G (d,p) & 1.381 & 1.314 & 1.464 & 1.233 & 1.414 & 111.6 & 105.9 & 124.3 & 117.8 & 179.1 & 179.4 & 82.1 & 0.5 & 176.9 \\
\hline B3LYP/6-31+G (d,p) & 1.380 & 1.314 & 1.465 & 1.234 & 1.416 & 111.5 & 106.1 & 124.1 & 117.8 & 179.1 & 179.6 & 79.5 & 0.4 & 177.7 \\
\hline B3LYP/6-31G(d,p) ${ }^{\mathrm{a}}$ & 1.379 & 1.321 & 1.397 & 1.302 & 1.417 & 111.1 & 105.8 & 120.9 & 120.0 & 173.7 & 178.5 & 79.5 & 0.0 & 176.7 \\
\hline B3LYP/6-31G (d,p) & 1.379 & 1.322 & 1.397 & 1.286 & 1.415 & 111.2 & 105.0 & 122.5 & 119.4 & 169.6 & 178.1 & 78.1 & 0.0 & 174.6 \\
\hline EXP & 1.382 & 1.311 & 1.451 & 1.233 & 1.415 & 111.7 & 105.9 & 122.9 & 118.2 & 174.0 & 179.9 & 89.4 & 5.0 & 164.7 \\
\hline
\end{tabular}

${ }^{a}$ Nitro anion radical optimization considered solute-solvent interaction on the C-PCM model at level B3LYP/6-31g (d,p), ${ }^{\mathrm{b}}$ Nitro anion radical optimization in vacuum at level B3LYP/6-31g (d,p), ${ }^{\mathrm{c}}$ Bond length in angstrom, $\AA$, ${ }^{\mathrm{d}}$ Angle y dihedral angle in degree. 
Table 2. Experimental and computed hyperfine coupling constants (hfcc) values by JNI 1

\begin{tabular}{|c|c|c|c|c|c|c|c|}
\hline Methodology & $\mathrm{N} /$ gauss & $\mathrm{N}-1$ '/ gauss & $\mathrm{N}-2$ '/ gauss & H-4'/ gauss & H-6'/ gauss & H-7'/ gauss & Dipole / deybe \\
\hline UB3LYP/6-31G(d,p) ${ }^{\mathrm{a}}$ & 4.17 & 0.11 & 0.37 & 9.01 & 0.84 & 0.37 & 24.705 \\
\hline UB3LYP/6-31+Ga & 7.56 & 0.38 & 0.25 & 7.50 & 1.58 & 1.00 & 27.976 \\
\hline UB3LYP/6-31G(d,p) & 7.15 & 0.00 & 0.23 & 7.32 & 1.70 & 1.14 & 28.865 \\
\hline UB3LYP/6-31+G & 11.30 & 0.10 & 0.39 & 6.64 & 2.15 & 1.40 & 31.172 \\
\hline UB3LYP/6-31G(d,p) ${ }^{\mathrm{c}}$ & 7.83 & 0.08 & 0.34 & 6.64 & 2.18 & 1.42 & 30.403 \\
\hline $\mathrm{UB} 3 \mathrm{LYP} / 6-31+\mathrm{G}(\mathrm{d}, \mathrm{p})^{\mathrm{c}}$ & 9.48 & 0.17 & 0.28 & 6.04 & 1.97 & 1.22 & 31.907 \\
\hline $\mathrm{UB} 3 \mathrm{LYP} / 6-31+\mathrm{G}(\mathrm{d})^{\mathrm{c}}$ & 9.49 & 0.17 & 0.28 & 6.10 & 2.00 & 1.23 & 31.901 \\
\hline UB3LYP/6-31+G ${ }^{c}$ & 12.02 & 0.17 & 0.42 & 6.26 & 2.23 & 1.38 & 32.562 \\
\hline UB3LYP/6-311G(d,p) ${ }^{c}$ & 5.30 & 0.01 & 0.16 & 5.96 & 1.44 & 0.90 & 30.712 \\
\hline UB3LYP/IGLO-II ${ }^{c}$ & 6.80 & 0.06 & 0.19 & 6.01 & 1.60 & 0.99 & 31.630 \\
\hline UB3LYP/IGLO-III ${ }^{\mathrm{c}}$ & 7.75 & 0.10 & 0.20 & 5.42 & 1.50 & 0.91 & 32.074 \\
\hline UB3LYP/EPR-III' (JNI 3) & 7.18 & 0.14 & 1.20 & 5.08 & 1.76 & 0.69 & 29.014 \\
\hline UB1LYP/6-31G(d,p) ${ }^{c}$ & 9.03 & 0.07 & 0.37 & 7.18 & 2.18 & 1.54 & 31.204 \\
\hline $\mathrm{UB} 1 \mathrm{LYP} / 6-31+\mathrm{G}(\mathrm{d}, \mathrm{p})^{\mathrm{c}}$ & 10.84 & 0.17 & 0.37 & 6.49 & 2.25 & 1.51 & 32.628 \\
\hline UB1LYP/6-31+G ${ }^{c}$ & 13.49 & 0.15 & 0.54 & 6.78 & 2.55 & 1.71 & 33.281 \\
\hline UB1LYP/IGLO-II ${ }^{c}$ & 8.45 & 0.07 & 0.31 & 6.41 & 2.06 & 1.43 & 31.732 \\
\hline UB1LYP/IGLO-III ${ }^{\mathrm{c}}$ & 9.38 & 0.12 & 0.31 & 5.80 & 1.89 & 1.29 & 32.163 \\
\hline PBE1PBE/6-31G(d,p $)^{c}$ & 8.58 & 0.03 & 0.37 & 7.76 & 2.27 & 1.66 & 31.282 \\
\hline PBE1PBE $/ 6-31+G(d, p)^{c}$ & 10.21 & 0.13 & 0.37 & 7.07 & 2.37 & 1.66 & 32.572 \\
\hline PBE1PBE /6-31+G ${ }^{\mathrm{c}}$ & 12.88 & 0.11 & 0.54 & 7.20 & 2.66 & 1.83 & 33.256 \\
\hline JNI 1 exp. ${ }^{d}$ & 12.32 & - & ca. 0.44 & 4.49 & 2.22 & 1.76 & \\
\hline JNI 3 exp. ${ }^{d}$ & 10.54 & 0.20 & 1.18 & 4.73 & 2.37 & 1.67 & \\
\hline
\end{tabular}

${ }^{\mathrm{a}}$ Single point calculation in vacuum from optimized geometry in vacuum at level B3LYP/6-31g (d,p) ${ }^{\mathrm{b}}$ Single point calculation considered solute-solvent interaction with C-PCM model from optimized geometry in vacuum at level B3LYP/6-31g (d,p), ${ }^{c}$ Single point calculation considered solute-solvent interaction from optimized geometry employed C-PCM model at level B3LYP/6-31g (d,p) ${ }^{\mathrm{d}} \mathrm{hfccs}$ experimental values using DMSO like solvent, see ref. 2.

Also, it has been reported that hfccs are quite sensitive to the polarization due to the solvent..$^{25}$ Direct solvent effects on the calculated hfccs values using UB3LYP methodology and different basis sets are reported in Table 1. In this context, "direct effect" indicates the effect of the induced polarization by the solvent on the solute's wavefunction, while keeping the geometry optimized in vacuum. The analysis shows that the dipolar moment changes strongly from the gas phase to DMSO, indicating that radical structures are being strongly polarized by the presence of a dielectric environment (see Table 2). These strong polarizations on the electronic structure directly affect the spin distribution density of the nitro anion radicals. It may be considered that choosing an appropriate basis set is a crucial fact for the proper description of the solute-solvent interactions. ${ }^{26-31}$

Unfortunately, it was not possible to use the EPR-III basis sets on the calculation of hfccs for JNI 1, due to a lack of parameterers for the sulphur atoms. Consequently, JNI 3 was employed in order to evaluate the behavior of this basis set. Table 2 shows that incorporating solute-solvent interactions into the calculation of hfcss, yield better results. However, using larger basis set did not improve hfecs values, which still are far from the experimental values for the nitrogen atom of the nitro group.

Interestingly, the calculated hfccs values that showed a good agreement with the experimental data were the ones obtained using a small basis set without polarization functions, such as $6-31+\mathrm{G}$ (see Figure 2B). Moreover, the insertion of polarization functions (such as $\mathrm{d}$ or $\mathrm{d}$ and p) did not improve hfccs values either. It is probable that the insertion of these kinds of functions generates a greater delocalization in the aromatic system; with an underestimation of the hfccs values for the nitrogen atom of the group nitro (see Table 2). In addition, the use of diffuse functions was an important factor for the appropriate description of the electronic properties of these types of anion radicals.

Using different basis set and different functional forms, the obtained deviations from the experimental values of the calculated hfccs showed clearly that none of the selected methodologies was able to reproduce the 
hfccs for $\mathrm{H}-4$ and $\mathrm{N}$ atom of the nitro group at same time. However, the best results were always obtained with basis sets including diffusion functions, improving to a great extent the description of hfccs for the nitrogen of the nitro group. These results are in agreement with previous reports indicating that the use of diffuse functions is an important factor in the description of bipolar molecules and anions that have a negative charge on heavy atoms. ${ }^{26-31}$ On the other hand, the effect of geometry reoptimization considering solvent effects, defined here as "indirect solvent effects", displays an increase in the $\mathrm{N}-\mathrm{O}$ bond length (of $0.016 \AA$ ) and a decrease in the $\mathrm{O}-\mathrm{N}-\mathrm{O}$ angle (of $1.6^{\circ}$ ). In addition, it is observed a slight increment on the hfccs $c a$. $0.6-0.8 \mathrm{G}$, which is largest for the nitrogen of the nitro group ca. $0.8 \mathrm{G}$. Although this variation improves the agreement with the experimental data, it is sufficiently small to be neglected in the analysis of general trends (see Table 2).

In summary, a polarizable environment has a strong influence on the spin density distribution of these anion radicals (5-NI). In addition, the basis set effect is a factor that should be considered in the calculation of these anion radicals, where the use of diffuse functions being the most important determinants.

All functionals employed here were able to describe properly the spin density, where the functional B3LYP showed the best results. Interestingly, the type of functional used was not so determinant into the hfccs computed values. Nevertheless, the type of basis set employed and the incorporation of solute-solvent interactions affects the calculation of hfccs significantly.

In order to to evaluate this methodology on other 5-NI derivatives, the study was extended to 3 -alcoxi and 5-nitroindazolones compounds (Figure 1). The results collected in Table 3, confirm the conclusions drawn for the model for JNI 1, leading to the proposal of that the abovementioned computational strategy could be extended to the whole series of 5-NI with greater confidence.

\section{Calculation of electronic properties}

Due to the importance of the electronic parameters of the 5-nitroheterocycles on the antichagasic activity and the accurate description of the geometrical data for the neutral forms and that of spin density distribution for radical forms showed by the selected conformers, we used both forms to explore the possible relationships between the antichagasic activity and the molecular electronic features. The EA is an important descriptor for reactivity that determines the local reactivity of a molecule when it encounters an electron. Besides, we also calculated properties related with the hydrophobicity of the compounds such as dipole moment and the partition coefficient.

It is known that nitroheterocycle compounds require a metabolic activation through the reduction of the nitro substituent; experimental evidence postulates this reduction as a key step. ${ }^{13}$ When a nitro compound is reduced, the electron enters in the LUMO orbital; therefore, the associated energy will indicate the likelihood of the reduction process for these compounds. For the 5-NI derivatives the LUMO values ranged between 0.118 hartree (for the more active compound, JNI 20) and 0.113 hartree (for the lower active compound JNI 3, against T. cruzi). The difference among these values indicates that if the more active compound is reduced all the other compounds of this

Table 3. Experimental and computed hyperfine coupling constants (hfcc) values by seven JNI

\begin{tabular}{|c|c|c|c|c|c|c|c|c|}
\hline \multirow[t]{2}{*}{ Method } & \multirow[t]{2}{*}{ hfcc / gauss } & \multicolumn{7}{|c|}{ Nitroindazole } \\
\hline & & JNI 1 & JNI 2 & JNI 3 & JNI 4 & JNI 6 & JNI $20^{*}$ & JNI $21^{*}$ \\
\hline \multirow[t]{6}{*}{ UB3LYP/6-31+g } & $\mathrm{N}$ & 12.02 & 11.50 & 12.01 & 11.98 & 12.20 & 11.85 & 11.44 \\
\hline & $\mathrm{N}-1$ & 0.17 & 0.24 & 0.32 & 0.21 & 0.19 & 0.21 & 0.07 \\
\hline & $\mathrm{N}-2$ & 0.42 & 1.29 & 1.22 & 0.39 & 0.42 & 0.42 & 0.35 \\
\hline & $\mathrm{H}-4$ & 6.26 & 5.23 & 5.38 & 6.20 & 6.13 & 6.10 & 6.52 \\
\hline & H-6 & 2.22 & 3.03 & 2.82 & 2.27 & 2.27 & 2.22 & 2.17 \\
\hline & $\mathrm{H}-7$ & 1.38 & 1.46 & 1.43 & 1.40 & 1.38 & 1.40 & 1.41 \\
\hline \multirow[t]{6}{*}{ Exp. ${ }^{a}$} & $\mathrm{~N}$ & 12.32 & 10.52 & 10.54 & 11.35 & 11.87 & 11.55 & 11.35 \\
\hline & $\mathrm{N}-1$ & 0.21 & 0.20 & 0.20 & 0.21 & 0.21 & 0.21 & 0.21 \\
\hline & $\mathrm{N}-2$ & 0.45 & 1.18 & 1.18 & 0.45 & 0.45 & 0.45 & 0.45 \\
\hline & $\mathrm{H}-4$ & 4.178 & 4.73 & 4.64 & 5.5 & 5.5 & 5.5 & 5.5 \\
\hline & H-6 & 2.047 & 2.37 & 2.36 & 2.00 & 2.00 & 2.00 & 2.00 \\
\hline & $\mathrm{H}-7$ & 1.671 & 1.18 & 1.18 & 1.10 & 1.10 & 1.10 & 1.10 \\
\hline
\end{tabular}

${ }^{\mathrm{a}}$ hfccs experimental values using DMSO like solvent, see ref. 2 . 

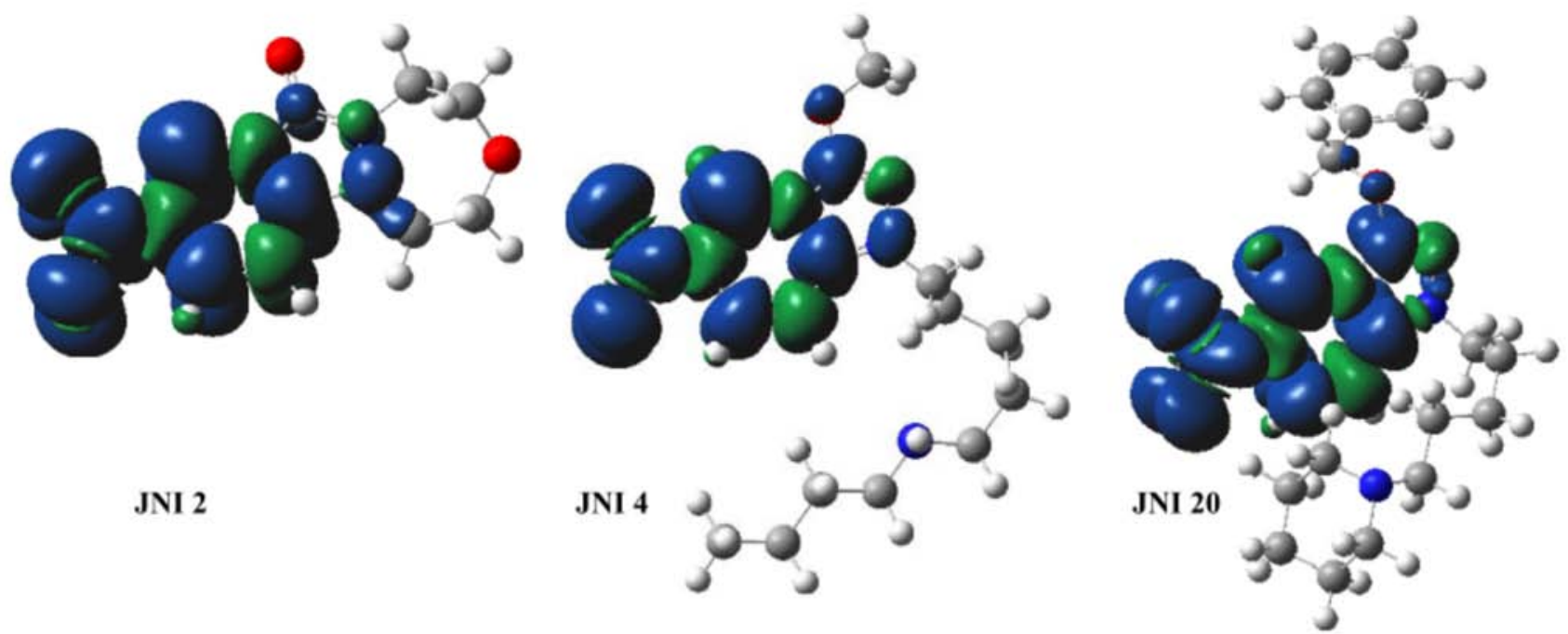

Figure 3. Spin density distribution on compounds: JNI 2 (inactive), JNI 4 (medium activity) and JNI 20 (active).
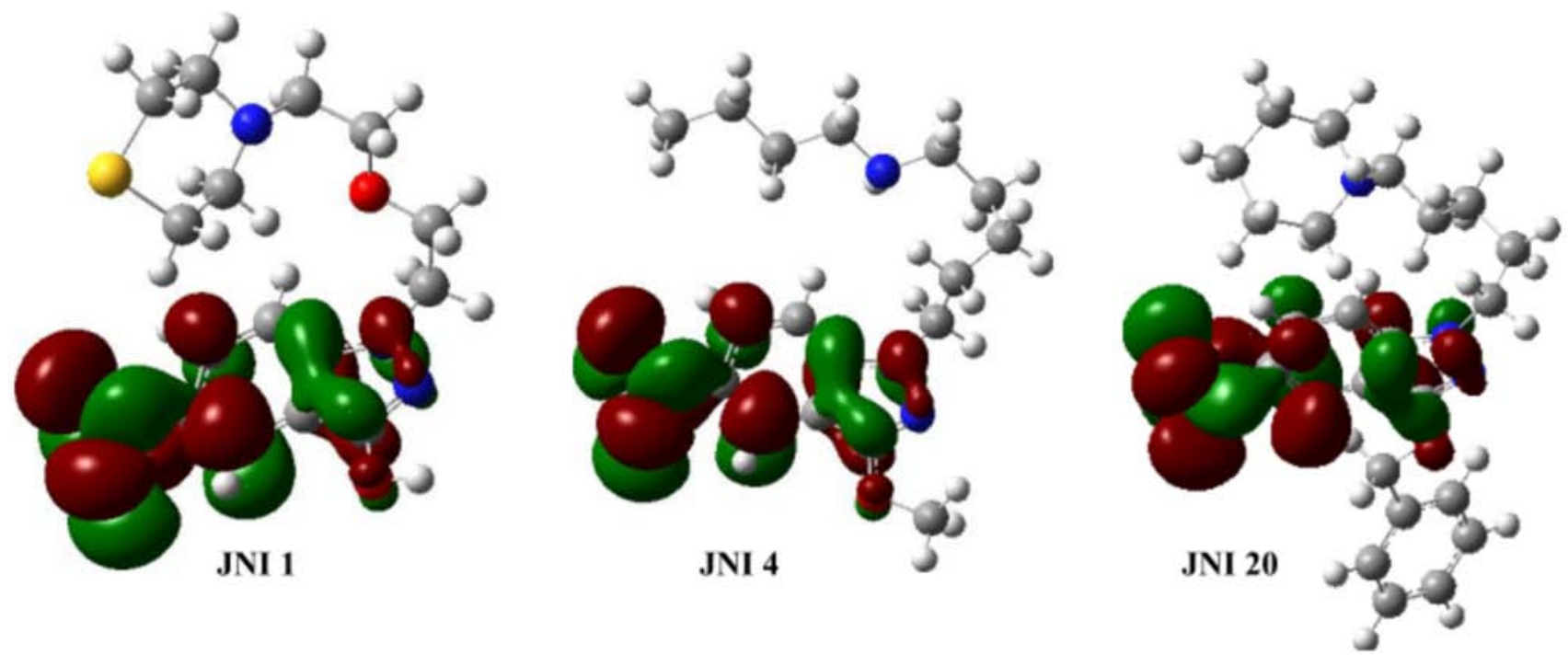

Figure 4. LUMO orbital distribution on compounds: JNI 1 (inactive), JNI 4 (medium activity) and JNI 20 (active) (online version in color).

family are going to be reduced also (see Figure 4). This is in agreement with the experimental reduction potentials which have a slight variation range of $0.1 \mathrm{~V} .{ }^{2}$ Nonetheless, EA displays a simple correlation (Pearson coefficient, $\mathrm{R}^{2}=0.91, \mathrm{n}=7$ ) with the Trypanosomal activity, indicating that compounds with lower EA displays higher activity. EA is a global property that indicates whether an anion is stable or unstable regards to an electron loss. In other words, the more active compounds (JNI 20 and 21) are able to produce more reactive radical anions. Calculated condensed Fukui functions for nucleophilic attacks $\left(f^{+}\right)$, showed that the oxygen of the nitro group have the higher values, thus being the most reactive moiety of the molecules. This behavior is observed for all the systems under study, indicating the feasibility of the reduction process.
Hydrophobicity can be related to the activity of nitroheterocycles. The associated parameters are the dipole moment and the partition coefficient. Inactive compounds (JNI 1-3) showed higher dipole moments but it was not possible to establish a valid simple correlation between these parameter and the antibacterial activity (Pearson coefficient, $\mathrm{R}^{2}=0.63, \mathrm{n}=7$ ). 3-alkoxy-5-NI derivatives, JNI 4-6 and JNI 21, cover all the range of biological activities for T. cruzi, and they have very similar dipole moment values, ranging from 10.641 (D) to 10.746 (D).

The partition coefficient $(\mathrm{P})$ was calculated as $\log \mathrm{P}$ using Villar method, implemented in Spartan '04 package. ${ }^{17,18}$ For our 5-NI derivatives we have found that compounds with $\log \mathrm{P}$ values lower than 2.5 have shown to 
Table 4. Electronic and thermodynamic descriptors calculated at level B3LYP/6-31+g; biological activity on $T$. cruzi

\begin{tabular}{|c|c|c|c|c|c|c|c|c|c|c|}
\hline \multirow[t]{2}{*}{ JN I } & \multirow{2}{*}{$\begin{array}{l}\text { LUMO/ } \\
\text { hartree }\end{array}$} & \multirow[t]{2}{*}{$\mathrm{EA} / \mathrm{eV}^{\mathrm{a}}$} & \multirow[t]{2}{*}{$\log \mathrm{P}$} & \multirow{2}{*}{$\begin{array}{l}\text { Dipolar/ } \\
\text { debye }\end{array}$} & \multirow[t]{2}{*}{ GI $\%^{b}$} & \multicolumn{5}{|c|}{$f_{K}^{+}$} \\
\hline & & & & & & $\mathrm{N}$ & $\mathrm{O}$ & $\mathrm{O}$ & $\mathrm{N}-1$ & $\mathrm{~N}-2$ \\
\hline JNI 1 & -0.116 & 3.893 & 2.438 & 13.804 & 0 & 0.199 & 0.257 & 0.271 & 0.008 & 0.059 \\
\hline JNI 2 & -0.116 & 3.894 & 1.236 & 11.582 & 6 & 0.206 & 0.247 & 0.249 & 0.019 & 0.085 \\
\hline JNI 3 & -0.114 & 3.908 & 2.368 & 14.358 & 3 & 0.214 & 0.250 & 0.247 & 0.005 & 0.083 \\
\hline JNI 4 & -0.114 & 3.812 & 4.376 & 10.746 & 58 & 0.202 & 0.265 & 0.250 & 0.014 & 0.036 \\
\hline JNI 6 & -0.113 & 3.820 & 4.434 & 10.641 & 20 & 0.251 & 0.237 & 0.255 & 0.090 & -0.042 \\
\hline JNI 20 & -0.118 & 3.600 & 5.700 & 5.334 & 100 & 0.160 & 0.252 & 0.263 & 0.155 & -0.062 \\
\hline JNI 21 & -0.114 & 3.617 & 4.112 & 10.706 & 80 & 0.167 & 0.257 & 0.265 & 0.158 & -0.063 \\
\hline
\end{tabular}

${ }^{\mathrm{a}}$ EA = Electron Affinity; EA = Energy (neutral) - Energy (radical), ${ }^{\mathrm{b}} \mathrm{GI}=$ Growth inhibition on T. cruzi. See ref. 32.

be inactive (compounds JNI 1-3) whereas compounds with values higher than 4.0 have shown to be active (compounds JNI 4, 5, 20-21). The highest $\log \mathrm{P}$ value, 5.70, corresponds to the most active compound of the serie JNI 20.

Our results suggest that due to the high similarities of the LUMO values, we can not rely on these to explain completely the observed differences in the biological activities shown for this 5-NI derivatives family. However, our calculated EA values seem to point out that the stability of anions radical might be a relevant factor concerning their biological activity. On the other hand, the parameters related with the hydrophobicity (dipole moments and $\log \mathrm{P}$ ) indicate that hydrophobic interactions could be also an important factor to consider in the activity of this kind of compounds.

\section{Conclusions}

We found that DFT can accurately reproduce isotropic experimental hfccs for EPR 5-nitroindazole employing small basis set. The B3LYP functional in combination with $6-31+\mathrm{G}$ basis set and the incorporation of solutesolvent interactions (C-PCM model) is appropiated when predicting nitrogen hfccs for 5-nitroindazole radicals. The error compensation between this incomplete basis set and this functional can also contribute to a better agreement with experimental data. In addition, the calculation of hfccs for anion radicals of 5-nitroindazole is sensitive to the basis set used and it is an important factor to be considered. The insertion of polarization functions did not improve the calculation of hfccs values; however the use of diffuse functions must be taking into account. The descriptors derived from physicochemical properties such as $\log \mathrm{P}$ and dipole moments, mainly related to the hydrophobicity, indicated that the presence of hydrophobic groups constitute an important structural component in the antichagasic activity of these 5-NI derivatives.

\section{Acknowledgments}

This research was supported by FONDECYT 1071078 grant (Chile) and MECESUP UMC-0204. The authors thank RTPD network, Comisión Sectorial de Investigación Científica-UdelaR (Uruguay), PEDECIBA (Uruguay) and UCH-0408 for the scholarship to J.R. GAZT thanks to PROYECTO BICENTENARIO DE INSERCION A LA ACADEMIA CONICYT 2004.

\section{References}

1. Fermi, E.; Zeitschrift für Physik A Hadrons and Nuclei 1930, $60,320$.

2. Rodríguez, J.; Olea-Azar, C.; Barriga, G.; Folch, C.; Gerpe, A.; Cerecetto, H.; González, M.; Spectrochim. Acta Part A 2008, $70,557$.

3. Shundrin, L. A.; Starichenko, V. F.; Shchegoleva, L. N.; Shteingartz, V. D.; J. Struct. Chem. 2003, 44, 592.

4. Koch, W.; Holthausen, M. C. A Chemist's Guide to Density Functional Theory; Wiley-VCH, 2001.

5. J.B. Foresman; Frisch, A. Exploring Chemistry with Electronic Structure Methods; Gaussian, Inc.: Pittsburgh, PA, 1996.

6. Adamo, C.; Subra, R.; Di Matteo, A.; Barone, V.; J. Chem. Phys. 1998, 109, 10244.

7. Hermosilla, L.; Calle, P.; de la Vega, J. M. G.; Sieiro, C.; J. Phys. Chem. A 2005, 109, 1114.

8. Hermosilla, L.; Calle, P.; de la Vega, J. M. G.; Sieiro, C.; J. Phys. Chem. A 2006, 110, 13600.

9. Adamo, C.; Barone, V.; Chem. Phys. Lett. 1997, 274, 242.

10. Adamo, C.; Barone, V.; J. Chem. Phys. 1998, 108, 664.

11. Perdew, J. P.; Burke, K.; Ernzerhof, M.; Phys. Rev. Lett. 1996, 77, 3865.

12. D‘Amore, M.; Improta, R.; Barone, V.; J. Phys. Chem. A 2003 , 107,6264 . 
13. Olea-Azar, C.; Rigol, C.; Mendizabal, F.; Morello, A.; Maya, J. D.; Moncada, C.; Cabrera, E.; di Maio, R.; Gonzalez, M.; Cerecetto, H.; Free Radic. Res. 2003, 37, 993.

14. Rigol, C.; Olea-Azar, C.; Mendizabal, F.; Otero, L.; Gambino, D.; Gonzalez, M.; Cerecetto, H.; Spectrochim. Acta Part A 2005, 61, 2933.

15. Cuzzocrea, S.; Riley, D. P.; Caputi, A. P.; Salvemini, D.; Pharmacol. Rev. 2001, 53, 135.

16. Koppenol, W. H.; Free Radic. Biol. Med. 1993, 15, 645.

17. Wavefunction Inc: 18401 Von Karman Avenue, Suite 370 , Irvine, California 92612, USA.

18. PC Spartan '04 User's Guide; Wavefunction Inc: California.

19. Frisch, M. J.; Trucks, G. W.; Schlegel, H. B.; Scuseria, G. E.; Robb, M. A.; Cheeseman, J. R.; Zakrzewski, V. G.; Montgomery, J. A.; Stratmann, R. E.; Burant, J. C.; Dapprich, S.; Millam, J. M.; Daniels, A. D.; Kudin, K. N.; Strain, M. C.; Farkas, O.; Tomasi, J.; Barone, V.; Cossi, M.; Cammi, R.; Mennucci, B.; Pomelli, C.; Adamo, C.; Clifford, S.; Ochterski, J.; Petersson, G. A.; Ayala, P. Y.; Cui, Q.; Morokuma, K.; Rega, N.; Salvador, P.; Dannenberg, J. J.; Malick, D. K.; Rabuck, A. D.; Raghavachari, K.; Foresman, J. B.; Cioslowski, J.; Ortiz, J. V.; Baboul, A. G.; Stefanov, B. B.; Liu, G.; Liashenko, A.; Piskorz, P.; Komaromi, I.; Gomperts, R.; Martin, R. L.; Fox, D. J.; Keith, T.; Al-Laham, M. A.; Peng, C. Y.; Nanayakkara, A.; Challacombe, M.; Gill, P. M. W.; Johnson, B.; Chen, W.; Wong, M. W.; Andres, J. L.; Gonzalez, C.; Head-Gordon, M.; Replogle, E. S.; Pople, J. A.; Gaussian, Inc: Pittsburgh, PA, 2001.
20. Becke, A. D.; Phys. Rev. A 1988, 38, 3098.

21. Lee, C. T.; Yang, W. T.; Parr, R. G.; Phys. Rev. B 1988, $37,785$.

22. Barone, V.; Cossi, M.; J. Phys. Chem. A 1998, 102, 1995.

23. Eriksson, L. A.; Wang, J.; Boyd, R. J.; Lunell, S.; J. Phys. Chem. 1994, 98, 792.

24. Gauld, J. W.; Eriksson, L. A.; Radom, L.; J. Phys. Chem. A 1997, 101, 1352

25. Rega, N.; Cossi, M.; Barone, V.; J. Am. Chem. Soc. 1997, 119, 12962.

26. Kirkwood, J. G.; Phys. Rev. 1934, 45, 0116.

27. Onsager, L.; J. Am. Chem. Soc. 1936, 58, 1486.

28. Wong, M. W.; Frisch, M. J.; Wiberg, K. B.; J. Am. Chem. Soc. 1991, 113, 4776

29. Wong, M. W.; Wiberg, K. B.; Frisch, M. J.; J. Am. Chem. Soc. 1992, 114, 523.

30. Wong, M. W.; Wiberg, K. B.; Frisch, M. J.; J. Am. Chem. Soc. 1992, 114, 1645

31. Wong, M. W.; Wiberg, K. B.; Frisch, M.; J. Chem. Phys. 1991, 95, 8991 .

32. Rodríguez, J.; Gerpe, A.; Aguirre, G.; Kemmerling, U.; Piro, O. E.; Arán, V. J.; Maya, J. D.; Olea-Azar, C.; González, M.; Cerecetto, H.; Eur. J. Med. Chem. 2009, 44, 1545.

Submitted: January 19, 2010 Published online: July 1, 2010 